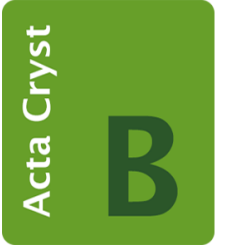

STRUCTURAL SCIENCE

CRYSTAL ENGINEERING

MATERIALS

Volume 73 (2017)

Supporting information for article:

Isothermal equation of state and high-pressure phase transitions of synthetic meridianiite (MgSO4-11D2O) determined by neutron powder diffraction and quasielastic neutron spectroscopy

Andrew Fortes, Felix Fernandez-Alonso, Matthew Tucker and lan Wood 


\section{Table S1}

Refined unit-cell parameters of $\mathrm{MgSO}_{4} \cdot 11 \mathrm{D}_{2} \mathrm{O}$ as a function of pressure.

\begin{tabular}{lllllllll}
\hline $\mathrm{T}(\mathrm{K})$ & $\mathrm{P}(\mathrm{MPa})$ & $a(\AA)$ & $b(\AA)$ & $c(\AA)$ & $\alpha\left(^{\circ}\right)$ & $\beta\left(^{\circ}\right)$ & $\gamma\left({ }^{\circ}\right)$ & $\mathrm{V}\left(\AA^{3}\right)$ \\
\hline
\end{tabular}

\section{Fortes et al., (2008)}

Uncertainty in $\mathrm{T}= \pm 0.05 \mathrm{~K}$, in $\mathrm{P}=\mathrm{n} / \mathrm{a}$ (ambient).

\begin{tabular}{lllllllll}
240 & 0.1 & $6.7495(1)$ & $6.8115(1)$ & $17.2920(3)$ & $88.135(1)$ & $89.491(1)$ & $62.687(1)$ & $705.97(1)$ \\
\hline
\end{tabular}

\section{Experiment 1: PEARL/HiPr, 2008}

Uncertainty in $\mathrm{T}= \pm 1 \mathrm{~K}$, in $\mathrm{P} \approx 5 \%$

\begin{tabular}{lllllllll}
240 & 192 & $6.735(1)$ & $6.776(1)$ & $17.269(3)$ & $88.38(2)$ & $89.60(2)$ & $62.60(2)$ & $699.4(3)$ \\
240 & 248 & $6.735(1)$ & $6.769(1)$ & $17.260(3)$ & $88.40(1)$ & $89.59(2)$ & $62.57(1)$ & $698.1(3)$ \\
240 & 257 & $6.732(2)$ & $6.764(2)$ & $17.255(4)$ & $88.42(2)$ & $89.56(2)$ & $62.57(2)$ & $697.1(3)$ \\
240 & 260 & $6.733(2)$ & $6.760(2)$ & $17.251(4)$ & $88.47(2)$ & $89.60(2)$ & $62.53(2)$ & $696.5(3)$ \\
240 & 496 & $6.721(1)$ & $6.728(1)$ & $17.225(2)$ & $88.70(1)$ & $89.60(1)$ & $62.39(1)$ & $690.0(1)$ \\
240 & 773 & $6.710(1)$ & $6.691(1)$ & $17.191(3)$ & $88.97(1)$ & $89.63(2)$ & $62.23(2)$ & $682.8(2)$ \\
\hline
\end{tabular}

\section{Experiment 2: PEARL/HiPr, 2009}

Uncertainty in $\mathrm{T}= \pm 1 \mathrm{~K}$, in $\mathrm{P} \approx 5 \%$

\begin{tabular}{lllllllll}
240 & 514 & $6.7234(4)$ & $6.7250(4)$ & $17.224(1)$ & $88.733(5)$ & $89.578(6)$ & $62.339(5)$ & $689.59(8)$ \\
\hline
\end{tabular}

\section{Experiment 3: OSIRIS, 2011}

Uncertainty in $\mathrm{T}= \pm 0.1 \mathrm{~K}$, in $\mathrm{P}=0.3 \%$.

$\begin{array}{lllllllll}240 & 48.0 & 6.7479(2) & 6.8036(2) & 17.2850(6) & 88.175(3) & 89.509(3) & 62.650(2) & 704.48(2) \\ 240 & 103.5 & 6.7453(2) & 6.7947(2) & 17.2767(5) & 88.246(2) & 89.524(3) & 62.606(2) & 702.69(2) \\ 240 & 149.7 & 6.7430(2) & 6.7867(2) & 17.2680(5) & 88.306(2) & 89.519(3) & 62.584(2) & 701.16(2) \\ 240 & 200.2 & 6.7390(2) & 6.7784(2) & 17.2647(5) & 88.340(2) & 89.530(3) & 62.550(2) & 699.55(2) \\ 240 & 252.0 & 6.7366(2) & 6.7694(2) & 17.2554(5) & 88.397(2) & 89.532(3) & 62.523(2) & 697.84(2) \\ 240 & 305.5 & 6.7325(2) & 6.7603(2) & 17.2515(5) & 88.460(2) & 89.556(2) & 62.497(2) & 696.18(2) \\ 240 & 351.0 & 6.7292(2) & 6.7533(2) & 17.2450(5) & 88.502(2) & 89.561(2) & 62.468(2) & 694.69(2) \\ 240 & 409.8 & 6.7252(2) & 6.7430(2) & 17.2399(5) & 88.569(2) & 89.566(3) & 62.461(2) & 692.99(2) \\ 240 & 451.8 & 6.7254(2) & 6.7367(2) & 17.2311(5) & 88.607(2) & 89.561(3) & 62.439(2) & 691.88(2) \\ 240 & 499.8 & 6.7236(2) & 6.7295(2) & 17.2242(5) & 88.661(2) & 89.566(3) & 62.404(2) & 690.48(2) \\ 240 & 550.0 & 6.7218(1) & 6.7218(1) & 17.2184(3) & 88.709(1) & 89.582(2) & 62.371(1) & 689.08(1)\end{array}$




\section{Pressure calibration using a revised equation of state for $\mathrm{Pb}$}

The $\mathrm{Pb}$ equation of state employed in this work was derived from a synthesis of literature values for the ambient-pressure thermal expansivity, and ultrasonic determinations of the temperature dependence of the bulk modulus and its first pressure derivative (see overleaf). The principal improvement in our implementation of this equation of state over that described previously (Fortes et al., 2007, 2012) lies in the robust propagation of errors.

The pressure is determined using a $3^{\text {rd }}$-order Birch-Murnaghan equation of state,

$$
\mathrm{P}_{\mathrm{V}, \mathrm{T}}=\frac{3}{2} \mathrm{~K}_{0, \mathrm{~T}}\left(x^{7 / 3}-x^{5 / 3}\right) \cdot\left[1+\frac{3}{4}\left(\mathrm{~K}_{0, \mathrm{~T}}^{\prime}-4\right)\left(x^{2 / 3}-1\right)\right]
$$

where $x=\mathrm{V}_{0, \mathrm{~T}} / \mathrm{V}_{\mathrm{P}, \mathrm{T}}$; and the unit-cell volume, $\mathrm{V}_{0, \mathrm{~T}}$, the isothermal bulk modulus, $\mathrm{K}_{0, \mathrm{~T}}$, and its first pressure derivative, $\mathrm{K}_{0, \mathrm{~T}}^{\prime}$, are found from temperature dependent polynomials; The second pressure derivative of the bulk modulus, $\mathrm{K}_{0,0}^{\prime \prime}$, is assumed to be independent of temperature.

$$
\begin{array}{cll}
\mathrm{V}_{0, \mathrm{~T}}=\mathrm{V}_{0,0}+a \mathrm{~T}+b \mathrm{~T}^{2} & \mathrm{~V}_{0,0} & 121.41813 \pm 0.00013 \AA^{3} \\
& a & 1.05822 \pm 0.00007 \times 10^{-2} \AA^{3} \mathrm{~K}^{-1} \\
& b & 3.493 \pm 0.004 \times 10^{-6} \AA^{3} \mathrm{~K}^{-2} \\
\mathrm{~K}_{0, \mathrm{~T}}=\mathrm{K}_{0,0}+c \mathrm{~T}+d \mathrm{~T}^{2} & \mathrm{~K}_{0,0} & 41.725 \pm 0.009 \mathrm{GPa} \\
& c & -2.544 \pm 0.004 \times 10^{-2} \mathrm{GPa} \mathrm{K}^{-1} \\
& d & -2.76 \pm 0.24 \times 10^{-6} \mathrm{GPa} \mathrm{K}^{-2} \\
\mathrm{~K}_{0, \mathrm{~T}}^{\prime}=\mathrm{K}_{0,0}^{\prime}+e \mathrm{~T} & \mathrm{~K}_{0,0}^{\prime} & 5.39 \pm 0.25 \\
& e & 0.0011 \pm 0.001 \mathrm{~K}^{-1}
\end{array}
$$

In a typical high-pressure experiment carried out on PEARL using the Paris-Edinburgh press, it is usual to obtain an uncertainty of $\sim 0.05 \%$ in the $\mathrm{Pb}$ unit-cell volume and $\sim 0.3 \%$ in temperature; the propagated error in the pressure is then approximately $3 \%$.

\section{References}

Our previous application of the $\mathrm{Pb}$ equation of state is given in:

Fortes, A. D., I. G. Wood, M. Alfredsson, L. Vočadlo, K. S. Knight, W. G. Marshall, M. G. Tucker, and F. FernandezAlonso (2007) The high-pressure phase diagram of ammonia dihydrate. High Press. Res. 27(2), 201-212 (doi:10.1080/08957950701265029), and Corrigendum (doi:10.1080/08957959.2012.673603). 


\section{S U P PLEMENTAR Y MATERIAL}

\section{Thermal expansion of $\mathrm{Pb}$}

D'Heurle, R. Feder, and A. S. Nowick (1963) Equilibrium concentration of lattice vacancies in lead and lead alloys. $J$. Phys. Soc. Japan Suppl. II., 18, 184-190.

Feder, R., and A. S. Nowick (1958) Use of thermal expansion measurements to detect lattice vacancies near the melting point of pure lead and aluminium. Phys. Rev. 109(6), 1959-1963 (doi:10.1103/PhysRev.109.1959).

Nix, F. C., and D. MacNair (1942) The thermal expansion of pure metals. II: molybdenum, palladium, silver, tantalum, tungsten, platinum, and lead. Phys. Rev. 61(1-2), 74-78 (doi:10.1103/PhysRev.61.74).

Rubin, T., H. L. Johnston, and H. W. Altman (1962) The thermal expansion of lead. J. Phys. Chem. 66(2), 266-268 (doi:10.1021/j100808a018).

Stokes, A. R., and A. J. C. Wilson (1941) The thermal expansion of lead from $0{ }^{\circ} \mathrm{C}$ to $320{ }^{\circ}$ C. Proc. Phys. Soc. 53(6), 658-662 (doi:10.1088/0959-5309/53/6/304).

Touloukian, Y. S., Kirby, R. K., Taylor, R. E., \& Desai, P. D. (1975) In, Thermal Expansion, Metallic Elements and Alloys, Vol. 12 of TPRC series on thermophysical properties of matter (Eds. S. Touloukian and C. Y. Ho), Plenum, New York.

Uffelman, F. L. (1930) The expansion of metals at high temperatures. Phil Mag. [Ser. 7], 10(65), 633-659 (doi:10.1080/14786443009461615).

Van Duijn, J., and J. Van Galen (1957) Influence of vacancies on the thermal expansion of lead near the melting point. Physica 23(6-10), 622-624 (doi:10.1016/S0031-8914(57)93541-3).

\section{Elastic constants of $\mathrm{Pb}$}

Goens, E., and J. Weerts (1936) Hauptelastizitätskonstantan des Einkristalls von Kupfer, Gold und Blei. Physikalische Zeitschrift 37, 321-326.

Miller, R. A., \& Schuele, D. E. (1969) The pressure derivatives of the elastic constants of lead. J. Phys. Chem. Solids 30, 589-600 (1969) (doi:10.1016/0022-3697(69)90014-6).

Pautomo, Y. (1963) On the temperature variation of volume. Ann. Acad. Sci. Fennicce Ser. A VI, Phys. 129, 7-45.

Prasad, S. C., and W. A. Wooster (1956) The elasticity of single crystals of lead. Acta Cryst. 9(1), 38-42 (doi:10.1107/S0365110X56000073).

Swift, I. H., and E. P. T. Tyndall (1942) Elasticity and creep of Pb single crystals. Phys. Rev. 61(5-6), 359-364 (doi:10.1103/PhysRev.61.359).

Vold, C. L., M. E. Glicksman, E. W. Kammer, and L. C. Cardinal (1977) The elastic constants for single-crystal lead and indium from room temperature to the melting point. J. Phys. Chem. Solids 38(2), 157-160 (doi:10.1016/00223697(77)90159-7).

Waldorf, D. L., \& Alers, G. A. (1962). Low temperature elastic moduli of lead. J. Appl. Phys. 33(11), 3266-3269 (1962) (doi:10.1063/1.1931149).

\section{High-pressure studies of $\mathrm{Pb}$}

Bridgman, P.W. (1923) The compressibility of thirty metals as a function of pressure and temperature. Proc. Am. Acad. Arts Sci. 58(5), 165-242 (doi:10.2307/20025987).

Bridgman, P.W. (1945a) The compression of twenty-one halogen compounds and eleven other simple substances to 100,000 kg/cm². Proc. Am. Acad. Arts Sci. 76(1), 1-7 (doi:10.2307/20023492).

Bridgman, P.W. (1945b) The compression of sixty-one solid substances to $25,000 \mathrm{~kg} / \mathrm{cm}^{2}$, determined by a new rapid method. Proc. Am. Acad. Arts Sci. 76(1), 9-24.

Mao, H. K., and P. M. Bell (1978) Study of lead at high pressure: compressibility and fixed-point transition between the FCC and HCP polymorphs under varying degrees of non-hydrostatic stress. Carnegie Inst. Yearbook 77, 842-848 (http://archive.org/details/yearbookcarne77197778carn).

Mao, H. K., Y. Wu, J. F. Shu, R. J. Hemley, and D. E. Cox (1990) High-pressure phase transitions and equation of state of lead to 238 GPa. Solid State Comm. 74(9), 1027-1029 (doi:10.1016/0038-1098(90)90479-U).

Vaida, S. N., and G. C. Kennedy (1970) Compressibility of 18 metals to 45 kbar. J. Phys. Chem. Solids 31(10), 23292345 (doi:10.1016/0022-3697(70)90247-7).

Kuznetsov, A. Z., Dmitriev, V., Dubrovinsky, L., Prakapenka, V., Weber. H. -P. (2002) FCC-HCP boundary in lead. Solid State Comm. 122(3-4), 125-127 (doi:10.1016/S0038-1098(02)00112-6). 